\title{
Exploration on High-quality Course Construction of Traditional Rock Mechanics Experimental Teaching
}

\author{
Huang Zhengjun, Zhang Lei, Liu Yu, Zhang Dong, Li Changhong \\ School of Civil and Resource Engineering, University of Science and Technology Beijing, Beijing, 100083
}

\begin{abstract}
Relying on national program of excellent couses of "rock mechanics and engineering", the experimental course of traditional rock mechanics will be gradually built into webdelivery for elaborate course with engineering experimental teaching characteristics by classfiying and integrating experimental facilities, improving experimental contents and programs and building the digital and web-based teaching resources and open teaching mode. At present, initial achievements have been made. It is of great significance to promote the overall development of the education and teaching of rock mechanics and faciliate the development of quality education and talents cultivation. Meanwhile, it will further increase the influence of our university in the education of rock mechanics, especially in experimental education.
\end{abstract}

Keywords-rock mechanics, experimental teaching, elaborate courses, open

\section{INTRODUCTION}

Since the enactment of major initiatives such as the expansion of college enrollment, the reform of management system in institutions of higher learning in 1999, our country has regarded the education of all-round development as the strategic priority for cross-century educational workers. After nearly 20 years of rapid development, higher education in China has ushered a new era with full-scale and rapid development and made lots of major achievements. Quality education is not only to impart and learn theoretical knowledge, but also to cultivate students' practical ability and creative thinking. As an indispensable part in the education and teaching in institutions of higher learning, experimental teaching aims to cultivate students' practical ability and creative spirit. Therefore, it is of great significance to improve experimental teaching and cultivate talents comprehensive abilities by building web-delivery for elaborate experimental courses, promoting the concept of experimental teaching with the cultivation of students' ability as its core and carrying out diversified reform on teaching mode ${ }^{[1-5]}$.

The distinctive specialized course "rock mechanics and engineering" in our university is evolved from "rock mechanics" which is offered since the establishment of the university. As the basic course of national key discipline of "mining engineering" in the university, it has become the basic and core course for many majors such as mining, civil engineering, safety, rock engineering, etc. and has wide and great influence in the education of "rock mechanics and engineering". After decades of concerted effort of multiple scholars, the research characteristics of rock mechanics and underground engineering in the field of rock mechanics and engineering have now been formed and fruitful research achievements have been made, which greatly promote the education and teaching of rock mechanics.

At present, "rock mechanics and engineering" has been built into national program of web-delivery for elaborate course. Experimental teaching of rock mechanics, as an indispensible component of courses, has always been paid much attention to in teaching and the key program to build. It aims to make students apply the basic theoretical knowledge learnt in classrooms through experimental teaching in a timely and effective manner, cultivate students' practical ability in experimental operation and consolidate theoretical knowledge ${ }^{[6-10]}$. Therefore, the web-delivery for elaborate course cannot be built without the one of experimental teaching which can be even built into independent webdelivery for elaborate course at national and provincial level. The excellent course of experimental teaching of rock mechanics will not only further perfect curriculum system and cultivate students' practical ability and creative thinking, but also manifest the comprehensiveness, synchronicity and innovation of quality education in an all-round manner. What's more, it will give full expression to and continue to increase our university's advantages and influence in the education and teaching of rock mechanics.

Relying on national web-delivery for elaborate course of "rock mechanics and engineering", this paper centers on each aspect of teaching resources of experimental teaching to include the experimental teaching of traditional rock mechanics into excellent course and build experimental elaborate course.

\section{THE CONSTRUCTION OF WEB-DELIVERY FOR ELABORATE COURSE}

\section{A. Classification and integration of experimental teaching facilities}

Experimental facilities are the foundation and hardware requirement for experimental teaching. As traditional engineering experiment, the upgrading of facilities for rock 
mechanics experiment will promote the reform of experimental theory and methods. Therefore, the high-quality course of experimental course cannot be built without the support of complete, adequate and advanced experimental facilities. The teaching and research of rock mechanics in our university have a long history. After decades of hard work of generations, relatively complete system for well-equipped and fully-functional experiment facilities has been formed, but there are also such problems as the admixture of new and old facilities, uneven distribution of the sets of facilities, disorder for use and affiliation of facilities, mixed use for the purpose of research and teaching, damaged facilities in the use of researches etc., which will affect the normal teaching.

Thus, we take the construction of this course as the opportunity to classify and integrate original facilities and newly-added experimental facilities of rock mechanics through the channel of repair and purchase for the purpose of researches. These facilities can be classified into 3 categories to use: basic teaching, creative teaching and advanced research as shown in Figure 1 and are used in the light of their classification and managed in a scientific way, thus forming comprehensive and advanced system of experimental teaching facilities. Basic teaching facilities include various regular instruments such as balance, drying oven, deformeter and regular universal testing machine and ordinary triaxial testing machine. Creative teaching facilities include testing machine for structural plane shear, testing machine for anchorage rheology, stiffness triaxial (single axis)testing machine and 3820 data acquisition system. Advance research facilities are mainly some imported equipment or advance domestic equipment with complicated functions which are hard to operate and maintain and costly, such as MTS815 testing system of rock mechanics, PCI-2 acoustic emission detector, RLJW-2000 testing machine for triaxial shear and rheology of rock. The facilities classified into these 3 categories will be mainly used and managed in undergraduate teaching, postgraduate teaching and researches conducted by doctoral students respectively. For example, basic teaching facilities are mainly used for undergraduate teaching, which can be operated and used independently by all students after simple instruction. Creative teaching facilities are mainly used for postgraduate teaching and scientific research, which can be used independently after systematic training. Advanced research facilities should be used independently after systematic and long period of training and being qualified by examinations. The whole facilities cost 10 million yuan with over 50 sets of equipment. The elaborate course characterized by classified use and scientific management of experimental facilities lays a solid foundation for promoting the webdelivery for elaborate course of experimental teaching of rock mechanics.

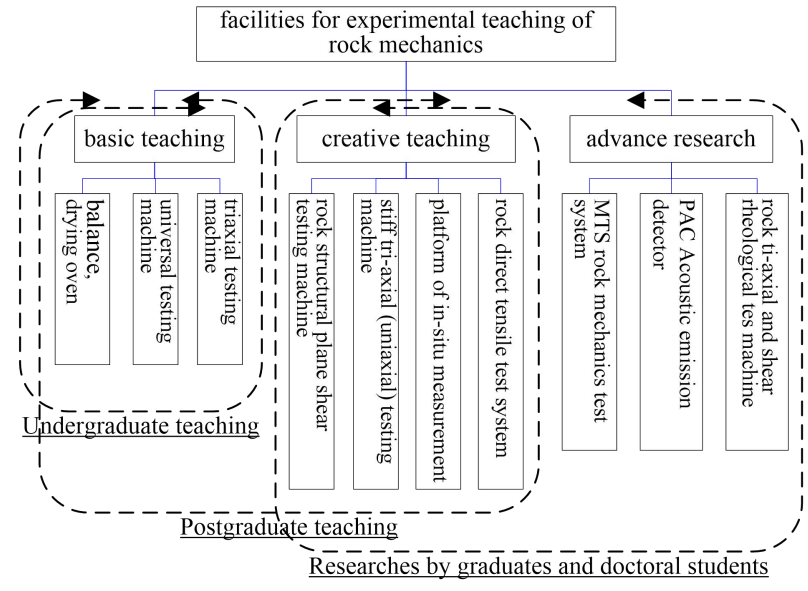

Fig. 1. Facilities system for experimental teaching of rock mechanics

\section{B. The perfection of experimental teaching contents}

The core of experimental teaching lies in the teaching contents. Besides complete and advanced experimental facilities, the web-delivery for elaborate experimental course of rock mechanics requires corresponding teaching contents. We rely on previous well-established national web-delivery for elaborate course of "rock mechanics and engineering" to rich and improve experimental teaching contents by centering on rock physical and mechanical property and combining with international and domestic current industrial standards and code of conduct while classifying and integrating experimental facilities. All regular testing programs and most comprehensive and creative experimental programs are included into the system of experimental teaching contents as shown in Figure 2.

Rock density, moisture content or water absorption, longitudinal wave velocity, uniaxial compressive strength, compressive deformation, splitting tensile strength, shear strength and triaxial compression test are the compulsory experimental programs for undergraduate teaching. All students need to practice in group. As the demonstrative experimental contents for undergraduate teaching and experimental programs for graduate students, implosion test, acoustic emission, direct tensile and water-physical property test should be demonstrated and explained to undergraduates and selected by graduates at random as optional programs. Rock rheology and multi-field coupling test are the research programs for graduates and doctoral students, which requires them to operate independently on the premise of completing the review of project design and operational training. The system of teaching contents cover 18 experimental programs and a book named Rock Mechanics and Engineering Experimental Guidebook that serves as the materials of teaching and research training, which reflects that the webdelivery for elaborate course is characterized by comprehensive, advance and creative experimental contents and method ${ }^{[10-11]}$ 


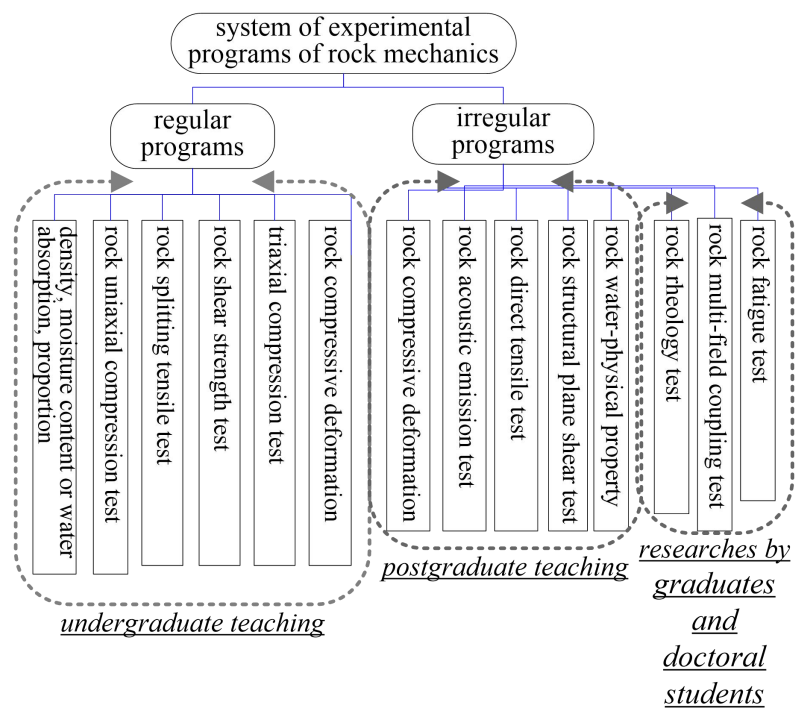

Fig. 2. Eexperimental teaching system of rock mechanics

\section{Digital and web-based teaching contents}

The major way to build high-quality course includes diversified teaching modes and methods. Experimental teaching mode featuring digital video supplements traditional face-to-face experimental teaching. Therefore, the first thing to develop diversified teaching modes and methods is to make videos for teaching contents and process. Relying on the platform of national excellent course of rock mechanics and engineering, we make digital teaching videos for related experimental teaching contents of rock mechanics, including the experiments of physical and mechanical property such as rock density, moisture content or water absorption, uniaxial or triaxial compressive strength, shear strength, tensile strength as shown in Figure 3 and 4. The video contents not only have the explanation of experimental methods and guide for experimental operation, but also students' actual operational process and processing and analysis on follow-up experimental data, which can combine with traditional experimental mode of "face-to-face instruction" in laboratories to further improve curriculum system and form diversified teaching mode ${ }^{[12-14]}$.

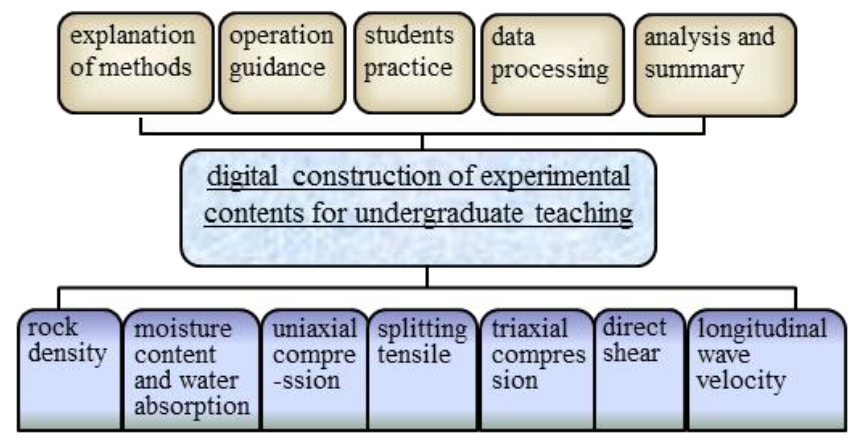

Fig. 3. Digital construction of experimental teaching

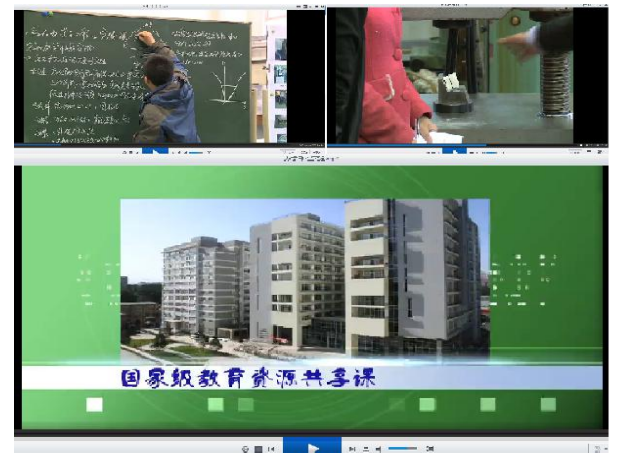

Fig. 4. Example of digital experimental teaching

The construction of high-quality course also includes webbased sharing of teaching resources in which the main task is to upload teaching videos in order to make more users study online, increase channels for users to learn knowledge and enhance the utilization of curriculum resources. This is also the important goal to build high-quality course.

Experimental teaching of rock mechanics is an inseparable part of "rock mechanics and engineering". In order to further perfect curriculum system and increase users to study the course, we will upload all videos of experimental teaching to the university's online course platform and "icourse" website-shared system for open online course of Chinese universities built by Ministry of Education as shown in Figure 5, which is the web-based experimental teaching resources ${ }^{[15]}$. After the web-based service, free online teaching resources are provided to users from both inside and outside university or even from abroad, which, on the one hand, can greatly boost experimental teaching of rock mechanics or even the whole education of rock mechanics and engineering, on the other hand, further enhance the influence of our university in the teaching and analysis of rock mechanics.

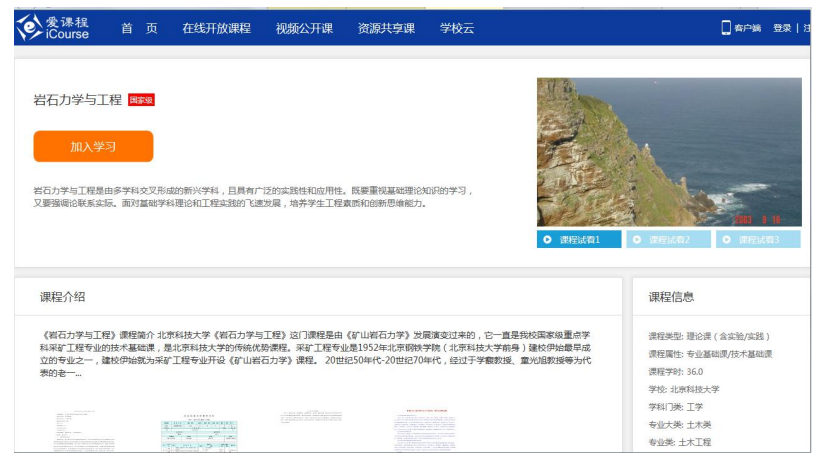

Fig. 5. Course introduction from shared website of icourse of national program of excellent and open course

\section{Exploration of open teaching mode}

The other goal to build experimental excellent course is to maximize teaching resources and serve more learning users. Over the past decade, open and shared teaching resources is explored and carried forward actively by the country, local governments and institutions of higher learning. Therefore, in order to response to the policy enacted by the country and colleges concerning open and shared excellent courses, we fully open and share all experimental facilities, experimental 
programs and related teaching resources to users in the university or even the whole nation in order to explore the open teaching mode as shown in Figure 6.

Open teaching is carried out as the reference of the classification of teaching facilities, which means that different facilities have different standards and requirements to meet the need of all students and other users to study experimental contents and apply for all kinds of experimental programs independently. In undergraduate teaching, before the classroom teaching, students should be informed to preview online to get to know experimental contents, which is helpful to carry out effective and safe experimental classroom teaching, provides platform and opportunity to review and restudy and is also of great significance for students to consolidate experimental theories and knowledge. In postgraduate teaching and the experimental programs for graduates' and doctors' researches, it should require them to study online and fully expose to trainings as soon as the courses begin and application is put forward. Only when they are qualified can they operate independently. The experimental teaching resources are totally open, including experimental facilities and programs opened in an all-round and timely manner, which is not only the requirement of webdelivery for elaborate course, but also riches the experimental teaching mode and increases learning approaches and scope for students and other users ${ }^{[16-17]}$.

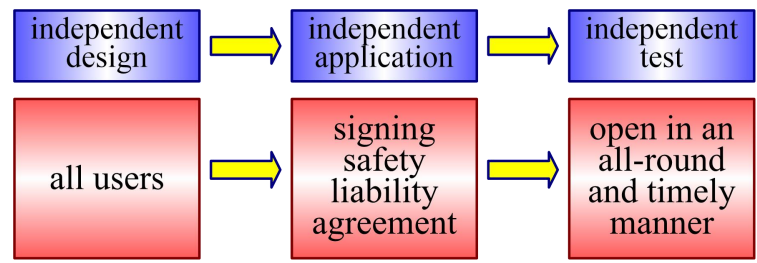

Fig. 6. Constructional path of open teaching mode

\section{INITIAL ACHIEVEMENTS OF THE CONSTRUCTION}

Since the launching of web-delivery for elaborate course of the experimental teaching of rock mechanics in 2014, the initial achievements have been made after 4 years of construction and improvement. A relatively complete and advance facility system has now been formed with comprehensive and perfect teaching contents and digital and web-based teaching videos. Additionally, open teaching mode has also been formed characterized by the combination of online self-study and face-to-face teaching . At present, such teaching mode has been applied into such majors for undergraduate as mining engineering and civil engineering, experimental teaching for postgraduate and researches. There are 10 experimental teaching programs for undergraduate in total with about 200 students participating in per year and more than 20 experimental teaching programs for postgraduate and researches with over 100 students per year. Meanwhile, there are over 20 scientific innovation programs for undergraduate inside and outside the university.

Digital and web-based teaching resources provide related users inside and outside the university with learning and training platform. There are now over 1,600 registered users and plenty of visitors. Online FAQ and classrooms interaction happen for several times. We have positive feedback from users inside and outside the university. With open teaching mode and totally opened teaching resources, there are over 200 cases for applying for various tests every year. And more than 70 students are trained to operate test independently and over 200 students can do under corresponding guidance.

\section{SUMMARY}

Relying on national program of web-delivery for elaborate couses of "rock mechanics and engineering", the experimental course of traditional rock mechanics will be gradually built into web-delivery for elaborate course with engineering experimental teaching characteristics by classfiying and integrating experimental facilities, improving experimental contents and projects and building the digital and web-based teaching resources and open-ended teaching mode. This, to a great extent, has solved the problems in the experimental teaching of rock mechanics in our university, promoted the overall development of the education and teaching of rock mechanics, facilitated the development of quality education and talents cultivation and increased our influence in rock mechanics.

\section{REFERENCES}

[1] Feng Wanlin, Duan Yuanyuan, Exploration on Web-Delivery for Elaborate Course in Institutions of Higher Learning[J]. Tsinghua Journal of Education, 2006, 27(2),115-118.

[2] Lu Qiuli, Sun Hua, Tian Yu et al, Investigation and Analysis on the Present Situation of National Program of Web-Delivery for Elaborate Course[J].Practice and Exploration, 2010,04,49-54,79-80.

[3] Huang Baoyu, Xiang Guoxiong, Analysis and Reflection on the Present Situation of National Program of Web-Delivery for Elaborate Course[J].China Higher Education Research, 2007,09:72-76.

[4] Zhang Daliang, Strengthening National Program of Web-Delivery for Elaborate Course with the High Quality as it Core[J]. China Higher Education Research, 2013,01:6-11.

[5] Yan Wenyong, Realization of Creative Education and Construction of Elaborate Course--Practice and Reflection on Web-Delivery for Elaborate Course of Higher Mathematics[J].Journal of Chengdu Electromechanical College, 2007,03:32-35.

[6] Zhang Penghui, Xiao Chaojie, The Present Situation of National Program of Web-Delivery for Elaborate Course and Enlightenment on the Construction of "National Program of Elaborate and Open Course"[J]. Resources Construction, 2012,04:76-78.

[7] Liu Liquan, Ding Lei, Review on Web-Delivery for Elaborate Course and National Program of Web-Delivery for Elaborate Course[J]. University Education Science, 2010,05:34-37.

[8] Zheng Shuguang, The Practice and Thinking on the Construction of Elite Open Courses--Taking "Economic Law" as an Example[J]. China Higher Education Research, 2015,09:89-93.

[9] Zhou Guangli, Zhang Wenjing, Retrospect on Seven Years' Construction of National Program of Web-Delivery for Elaborate Course--Initial Application of a Policy Evaluation Framework[J], Research in Higher Education of Engineering, 2010,01:36-45,52.

[10] Li Qi, Practice and Reflection on Web-Delivery for Elaborate Course of Materials Chemistry[J].Chinese Journal of Chemical Education, 2012,09:74-77.

[11] Zhao Yucheng, Zhang Kemeng, Experimental Teaching in WebDelivery for Elaborate Course of Theoretical Mechanics[J]. Work Study in Laboratory in Institutions of Higher Learning, 2003,04:12-13.

[12] Su Shaojing, Wang Yueke, Construction and Practice of Web-Delivery for Elaborate Course of Experimental Teaching for Engineering 
Graduates[J].Science and Technology Innovation Herald, 2008,28:183184.

[13] Chen Long, Zhang Yajun, Xu Liyan, On the Construction of the Course of "Digital Circuit Experiment"[J].Journal of Hangzhou Dianzi University (Social Science), 20107,03(4):73-76.

[14] Yuan Ping, Sun Jun, Wu Xiongwen, On the Construction of WebDelivery for Elaborate Course of Experimental Teaching[J].Jounal of Shanxi Medical University (Preclinical Medical Education Edition), 2010,12(S2):48-49.
[15] Wang Miansen, Strengthening the Construction of Web-Delivery for Elaborate Course under the Guidance of Modern Educational Concept-My Thought on Web-Delivery for Elaborate Course[J]. China University Teaching, 2009,05:20-22.

[16] Qu Jun, Zhu Xibao, Zhang Laihong, Innovation of the Experimental Teaching of Engineering Drawing Led by Web-Delivery for Elaborate Course[J].Research and Exploration in Laboratory, 2008,27(6):33-35.

[17] Yu Qianyuan, On the Experimental Teaching Reform in Quality Course Construction of Plant Physiology[J].Journal of Xichang College (Natural Science Edition), 2009,23(4):127-129. 